\title{
Level of Radiofrequency (RF) Radiations from GSM Base Stations and its Biological Effects on Albino Mice, Mus musculus
}

\author{
${ }^{* 1}$ OTITOLOJU, A A; ${ }^{2}$ OSUNKALU, V O; ${ }^{3}$ OBE, I A; ${ }^{4}$ ADEWALE, O A; ${ }^{5}$ AKINDE, O R \\ ${ }^{1 \& 3}$ Department of Zoology, Faculty of Science, University of Lagos, Akoka, Lagos, Nigeria \\ ${ }^{2}$ Department of Haematology \& Blood Transfusion, College of Medicine, University of Lagos, Idi-Araba, Lagos, Nigeria \\ ${ }^{4}$ Department of Physics, Faculty of Science, University of Lagos, Akoka, Lagos, Nigeria \\ ${ }^{5}$ Department of Morbid Anatomy, College of Medicine, University of Lagos, Idi-Araba, Lagos \\ *Email: bayotitoloju@yahoo.com
}

\begin{abstract}
Levels of radiofrequency radiations around two global systems for mobile communication (GSM) base stations located in the vicinity of a residential quarter and workplace complex were measured. The effects of the radiofrequency radiations on albino mice placed in exposure cages and located around the base stations over a six months period were carried out. The levels of radiofrequency (RF) radiations around the base stations were found to be between $488.51 \mathrm{mV} / \mathrm{m}$ to $625.49 \mathrm{mV} / \mathrm{m}$ compared to $59 \mathrm{mV} / \mathrm{m}$ in control stations. The results of the weight change experiment showed that over the 180 days of observation, there was weight gain in the exposed and control mice groups. Statistical comparisons of mean weight changes between exposed mice and control mice showed that there were no significant $(\mathrm{P}>0.05)$ differences between the weight of the test animals. The hematological studies revealed an elevation of white blood cell (WBC) counts in mice exposed to RF radiations compared to control group. There was however no significant $(\mathrm{P}>0.05)$ difference between the red blood cell counts in the exposed and control mice. There was also no significant $(P>0.05)$ difference in the hemoglobin and glucose levels in the blood of both exposed and control mice groups. The red blood cells in exposed mice were however found to contain a higher number of macrocytes, poikilocytes, polychromatic cells and fewer target cells than the control mice. Histological studies of the heart and kidney of exposed mice showed only slight tissues deformities in kidneys of exposed mice compared to control. The relevance of these findings in setting radiofrequency radiation exposure guidelines and the need for more studies with widely varying biological parameters is very necessary as Nigeria leaps further into the communication age. @JASEM
\end{abstract}

Due to the growing use of mobile phones and the explosive growth in the multitude of base stations to meet required efficiency from the networks, there is currently an increasing concern about the effects of electromagnetic exposure in the microwave range and radiofrequency (RF) radiation on exposed organisms and humans (Markov and Kostarakis, 2007). While several studies have indicated that exposure of biological systems to low level RF radiation caused adverse biological effects, other studies have indicated that at the current exposure level to RF radiations, no adverse effects were observed (Valberg et. al., 2007).

Although a lot of studies in literature generally indicate that the effects observed by most investigators in this area of study are attributable to hyperthermia, a condition whereby core body temperature is elevated due to exposure to high level of RF radiation under experimental conditions (Cheever et. al., 2001), there are a few studies which showed pathological effects arising from non-thermal interactions (Diem et. al., 2005). Some studies which have related large doses of radiofrequency electromagnetic radiation to genetic defects include Aitken et. al., 2005 (changes in the integrity of epididymal mitochondrial DNA); Tice et al., 2002 (increased micronuclei formations); Mashevich et. al., 2003 and Sykes et al., 2001 (increased chromosomal instability); Pacini et. al., 2002 (changes in morphology, gene expression and proliferation of fibroblast), Diem et al., 2005 (DNA *Corresponding Author: *Email: bayotitoloju@yahoo.com breakage) and Otitoloju et al., 2010 (increased sperm head abnormality ratios). Disturbance or alteration of the nervous systems have also been reported as a result of exposure to RF radiation and the consequent behavioural changes that may occur have been identified as early indicators of RF-related stress (Abdel-Rassoul et al., 2007). Abdel-Rassoul et al. (2007) concluded that inhabitants living nearby mobile phone base stations are at risk of developing neuropsychiatric problems and some changes in the performance of neurobehavioural functions either by facilitation or inhibition. Other studies have documented that RF exposure causes cell proliferation (Velizarov et al., 1999); enzyme activity (Paulraj and Behari, 2002, Barteri et al, 2004) and cell membrane permeability and ion homeostasis (Goltsov, 1999).

To the best of our knowledge and from literature searches carried out, there is little or no published information in Nigeria on the possible effects of the $\mathrm{RF}$ radiation on the organisms or humans inhabiting areas close to telecommunication base stations. Therefore, the objectives of this study are to determine the level of electromagnetic frequency radiation around GSM base stations located in residential and workplace quarters and determine the biological effects of the radiations and other activities around the GSM base stations on weight changes, blood parameters and tissue pathology on albino mice, Mus musculus. 


\section{MATERIALS AND METHODS}

Study Area: Three locations were selected for the experiment. Two of the locations have GSM base stations in the vicinity while the third location was a control site with no GSM location within a $300 \mathrm{~m}$ radius. For the two locations with GSM base station, one was located around a residential quarter and the other located around an office block complex.

Animal Breeding and Maintenance: Albino mice, Mus musculus, which served as the bioassay organisms were obtained from the Nigerian Institute of Medical Research (NIMR). Mice were fed with $40 \mathrm{~g}$ per day of mice feed in pellets. The mice were kept in cages for at least 14 days to acclimatise to experimental conditions $\left(29^{\circ} \mathrm{C} \pm 2^{\circ} \mathrm{C}\right.$ and Relative Humidity $-70 \% \pm 4 \%$ ) before commencement of bioassay.

Plastic cages (length $530 \mathrm{~cm}$, breath $350 \mathrm{~cm}$ by height $230 \mathrm{~cm}$ ) were designed for the study. Body weight of the mice was recorded at day $0,30,60,120,180$ and the mean weight was recorded. The exposure cages were located below the GSM base stations at a distance of $1 \mathrm{~m}$ away. Mice were divided into three groups containing 10 mice each. Each group were placed in the exposure cages and placed at the designated locations.

Measurement of Radiofrequency Radiation from GSM Base Stations: Total exposures due to frequency range for mobile phone base stations from $900 \mathrm{MHz}$ to $1800 \mathrm{MHz}$ were measured with the aid of a wide spectrum Aeritalia Radiofrequency Field Strength measuring meter at distances of $0,50,100$, 150, 200, 250 and 300m.

Biological Effects Studies: Weight Changes Experiment: At the various locations, each mouse was weighed daily for six months with the aid of a top loading compact weighing balance. The average weight gain or loss for each test animal per group was determined on days $0,30,60,120$ and 180 of the experiment.

Blood Parameters: White Blood Cell Counts: Blood was collected from the heart of the test animal using syringe of $2.5 \mathrm{ml}$ into EDTA anticoagulant bottle. The blood was diluted in $10 \mu$ l of blood sample to $190 \mu 1$ of Turk's solution (Glacial Acetic Acid tinted with gentian violet in aqueous solution) using micropipette to aspirate blood from the test tube in order to haemolyse the red blood cell therefore ensuring that only the white blood cells are being enumerated. White blood cells are counted microscopically using an improved Neubauer ruled counting chamber (haemocytometer). Micropipette was used to drop blood solution on the haemocytometer and was charged with water and cotton wool in a petri-dish and covered for 20minutes before and after use. A compound microscope was used to count and then the number of white blood cells per litre of blood was calculated.

Red Blood Cell Count: For the red blood cell count, $199 \mu \mathrm{l}$ of formol citrate ( $3 \mathrm{~kg}$ of trisodium citrate dissolved in distilled, $40 \%$ formaldehyde) is balanced with $1 \mu \mathrm{l}$ of sample blood sample. A micropipette was used to remove $1 \mu \mathrm{l}$ of the mixture for reading in Neubauer ruled counting chamber.

Blood Film and Morphology: Blood collected from the heart was smeared on a clean slide and fixed with Giemsa stain (90 days smear) and Leishman stain (filtered to remove sediment in the prepared stain) (180 days smear). The slide was allowed to dry and mounted on the microscope with oil immersion to increase the refractive index.

Blood Glucose Level: Blood glucose level was also determined with the aid of a glucose meter using a manufacturer provided strip and glucose level read out on the screen.

Histopathology Studies: For this studies, at predetermined day intervals (days 0, 120 and 180), 2 live mice per replicate making 4 per treatment including control were randomly selected and dissected. The heart and kidneys were carefully removed and fixed in Boiun's fluid pending further histology works. The fixed samples were transferred to phosphate buffer ( $\mathrm{pH}$ 6.8), after 7 hours of fixation in Boiun's fluid. The tissues were then dehydrated in graded alcohol, cleared in xylene before embedding in paraffin wax (melting point $56.0^{\circ} \mathrm{C}$ ). Serial sections of 2-5 um thickness was cut in rotary microtome then passed through xylene followed by absolute alcohol and water. The sections were stained with haematoxylin and eosin, dehydrated in graded alcohol, cleared in xylene and mounted in Canada balsam. The slides were left to dry on the hot plate for 24 hours before observation under the light microscope.

Statistical Analysis: Appropriately test results were subjected to analysis of variance (ANOVA) between the different treatment means and the control to test the null hypothesis that there was no difference between means for the various treatments and control. Further analysis by t-test was carried out only where there was a significant difference at the $5 \% \quad(\mathrm{P}<0.05)$ level of significance (taken as minimum requirement).

\section{RESULTS AND DISCUSSION}


In this study, the level of radiofrequency (RF) radiations emitted by the transmitters at the base station located around the workplace complex and residential quarters range from $488.51 \mathrm{mV} / \mathrm{m}$ to $625.49 \mathrm{mV} / \mathrm{m}$ respectively. The results of the radiofrequency measurements are presented in Fig 1 . The highest level of RF radiation based on electric field strength were detected around the base station located around the residential quarters. The RF radiation around the GSM base stations were alsu found to be significantly $(\mathrm{P}<0.05)$ higher than the $\mathrm{RF}$ radiations $(59 \mathrm{mV} / \mathrm{m})$ in the control stations where no base stations were located within $300 \mathrm{~m}$ radius. Comparison of these values to the International Commission on Non-Ionizing Radiation Protection (ICNIRP) guideline revealed that the RF radiation levels are about 90-120 folds lower than the commission's set guideline of $(40-60 \mathrm{~V} / \mathrm{m})$.

Table 1: White blood cell counts in mice after six months of exposure to radiations from GSM base stations.

\begin{tabular}{|c|c|c|}
\hline & \multicolumn{2}{|c|}{$\begin{array}{c}\text { White Blood Cells (WBC) } \\
\text { Count }\end{array}$} \\
\hline Locations & $\begin{array}{c}\text { average } \\
\left(\mathrm{x} 10^{9} / \mathrm{L}\right)\end{array}$ & Remarks \\
\hline $\begin{array}{c}\text { Residential } \\
\text { Quarters }\end{array}$ & $6.2^{*}$ & High \\
\hline $\begin{array}{c}\text { Workplace } \\
\text { Complex }\end{array}$ & $7.4^{*}$ & High \\
\hline Control Station & 1.8 & Normal \\
\hline
\end{tabular}

* indicate significant $(\mathrm{P}<0.05)$ difference in $\mathrm{WBC}$ count compared to control

Table 2: Red blood cell counts in mice after six months of exposure to radiations from GSM base stations.

\begin{tabular}{|l|l|l|}
\hline & Red Blood Cells (RBC) Count \\
\hline Locations & average $\left(\times 10^{12} / \mathrm{L}\right)$ & Remarks \\
\hline Residential Quarters & 4.31 & Normal \\
\hline Workplace Complex & 1.05 & High \\
\hline Control Station & 4.2 & Normal \\
\hline
\end{tabular}

Table 3: White and Red Blood abnormalities in mice after six months of exposure to radiations from GSM base stations.

\begin{tabular}{|l|l|l|}
\hline Locations & White Blood Cells & Red Blood Cells \\
\hline $\begin{array}{l}\text { Quarters } \\
\text { Complace }\end{array}$ & $\begin{array}{l}\text { No atypical form of } \\
\text { cells seen }\end{array}$ & $\begin{array}{l}\text { Poikilocyctes observed (cells of different shapes); Many } \\
\text { target cells; Haemoglobin level is normal. }\end{array}$ \\
\hline Control Station & $\begin{array}{l}\text { No atypical form of } \\
\text { cells seen }\end{array}$ & $\begin{array}{l}\text { Macrocytes (enlarged cells), Haemoglobin level is } \\
\text { normal; Few target cells; Many polychromatic cells was } \\
\text { observed. }\end{array}$ \\
\hline cells seen
\end{tabular}

It is however important to note that based on current knowledge, little can be said to be known about the effect of long term exposure that would be experienced by people living near these mobile phone base stations (Bortkiewicz et. al., 2004; AbdelRassoul et. al., 2007). According to Dasenbrock (2005), the author stated that if one were to be proposing new chemicals for commerce or new pharmaceuticals, the quality of available RF studies would not be acceptable for registration with responsible authorities. As a result, a number of agencies in different countries have come up with different safe limits or guidelines (Valberg et. al., 2007). For example, while the ICNIRP have set a limitation guideline of $40 \mathrm{~V} / \mathrm{m}-60 \mathrm{~V} / \mathrm{m}$, other countries such as France, Italy, Switzerland and Austria have set guidelines of $2 \mathrm{~V} / \mathrm{m}, 6 \mathrm{~V} / \mathrm{m}, 4-5 \mathrm{~V} / \mathrm{m}$ and $6 \mathrm{~V} / \mathrm{m}$ respectively. This wide variation in the set guidelines from different countries is a reflection of the state of information and risk perception of the potential health effect of the RF radiations. It is also a pointer to the need for adopting the precautionary principle - "better safe than sorry" in dealing with such an important matter that is likely to have profound impact on public health. It is therefore important for more studies to be carried out to determine the acute and long term effects of the present level of RF radiation that the public are exposed and estimate the level of danger or otherwise that can occur. 


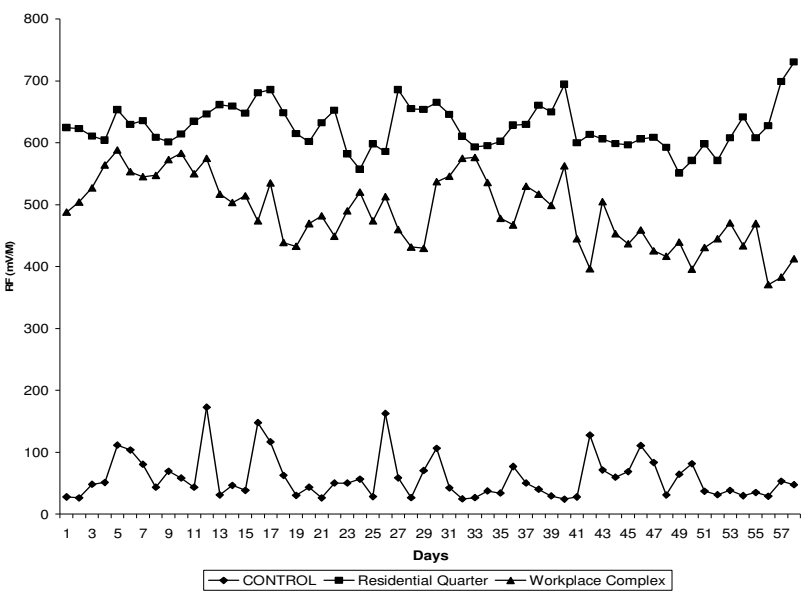

Fig. 1: Level of Radiofrequency Radiations from GSM base Stations at Different locations (Residential Quarters, Workplace Complex and Control Station).

The results of the haematological studies are presented in Tables 1-3. The results show that the white blood cell counts were found to be significantly $(\mathrm{P}<0.05)$ higher in the mice exposed radiofrequency radiations from GSM base stations than in control mice (Table 1). The elevation of white blood cell (WBC) counts may be related to the induction of a protective mechanism in the exposed mice to the effect of the RF radiation and other activities around the GSM base stations. Therefore, it could be deduced that exposure to radiofrequency radiations induces stress in exposed animals which led to the synthesis of abnormally high levels of white blood cells. Several studies including Pocock et. al. (1989), Hoffman et. al. (2004) and Jee et. al. (2005) have identified the white blood cell count as an integrated indicator of inflammatory stimuli on both acute and chronic time frames. It is elevated acutely by infection and other stresses or toxic exposures. A single measurement has been shown to predict risk for death and for specific diseases, including cancer and cardiovascular diseases. The elevation of white blood cell count is said to indicate infection, inflammation, trauma, stress, tissue destruction, diseases of the white blood cells themselves or disease of bone marrow or bone marrow failure. The significant elevation of the white blood cells is therefore a clear indication of a stress related effect in exposed animals and should prompt further investigations on the immunological effect of RF radiations on exposed population.

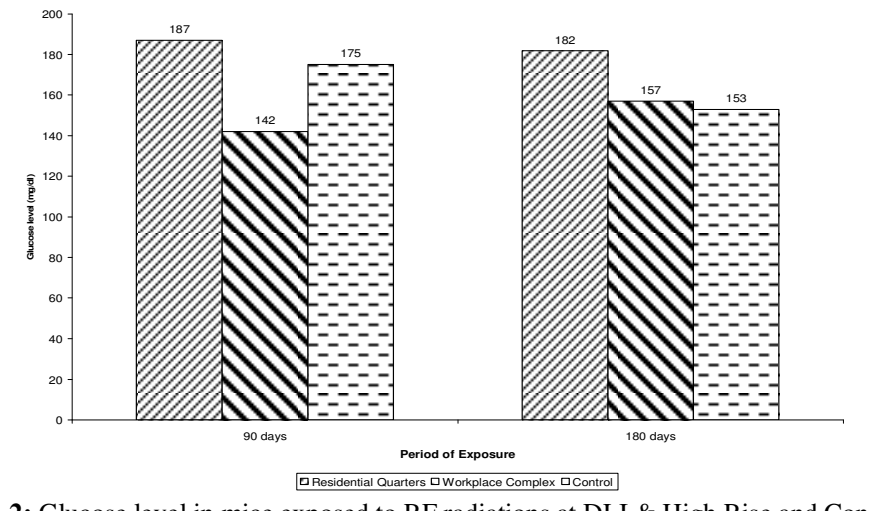

Fig. 2: Glucose level in mice exposed to RF radiations at DLI \& High Rise and Control

The exposure of the test animals to radiations from the GSM base stations did not have any significant effect on the red blood cell (RBC) counts (Table 2), haemoglobin level and blood glucose level (Fig. 2) in the exposed mice when compared to control group. In the studies on red blood cell morphology, there were abnormalities observed in the red blood cells of the exposed mice (Table 3). The observed deformities in the red blood cells include increase in number of macrocytes (enlarged cells), poikilocytes (cells of different shapes), polychromatic cells and target cells in exposed mice compared to the control group. These deformities in the red blood cells morphology show a possible link between exposure to nonionizing radiation and depression of the bone marrow as seen in clinical conditions such as multiple 
myeloma, clinical globulinaemia (reduced number of blood cells), myelofibrosis and thalassaemia (Hoffman et. al., 2004).

The results of the weight change experiments showed that over the 180 days of observation, there was weight gain in the mice exposed to radiations from
GSM base stations and those in the control site 3 ). The weight gain over the 6 months period of observation range from $5 \mathrm{~g}$ to $11 \mathrm{~g}$. Statistical comparisons of mean weight changes between exposed mice and control mice showed that there were no significant $(\mathrm{P}>0.05)$ differences between the weight of the test animals.

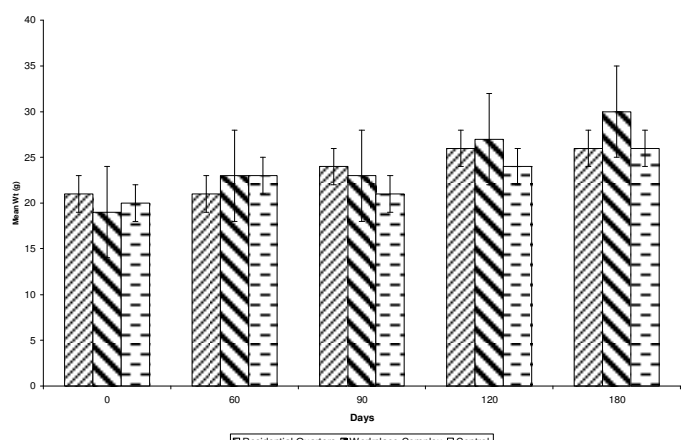

Fig. 3. Mean weight change in mice exposed to RF radiations and Control over a 6 months period of observation

Histopathological sections of heart and kidney in exposed animals indicate that there were only slight cellular deformations in the tissues of the exposed mice compared to control. Generally, there were no observed pathological changes in the heart of the mice exposed to radiofrequency radiation when compared to control. The kidney of the exposed mice however showed there were a lot polymorphonuclei cells seen though the ratio of nucleus to cytoplasm appears within the normal range. Renal capsule were also observed to be slightly distorted and there were also slight cellular alteration but not fully establish for the abnormality (Fig $4 \& 5$ ). Furthermore, the kidney of mice exposed to radiofrequency radiations were also found to be largely normal with slight cellular abnormality. These observations that exposure of organisms to RF radiations do not have any effect on some major biological indices have also been reported in literature (Maes et. al., 1995; Philips et. al., 1998; Garson et. al., 1999). In fact on the basis of available information in some literature, Valberg et. al. (2007) concluded that despite unavoidable uncertainty, there is no established existence of any adverse short-term or long-term health effects from the signals produced by base stations and local wireless networks.

The telecommunication industry is an essential attribute to modern day societies and a multi-billion dollar business. The controversies in reported findings are therefore not unexpected. It is however essential to widen the scope of biological parameters being investigated and also increase the period of observation so that the unavoidable uncertainties can be limited and 'collateral damages' due to application of electromagnetic frequency technologies reduced. It is however essential to note that at the global stage, the level of knowledge seem to indicate that mobile telephony RF exposure is unlikely to cause any severe adverse effect (Valberg et. al., 2007).

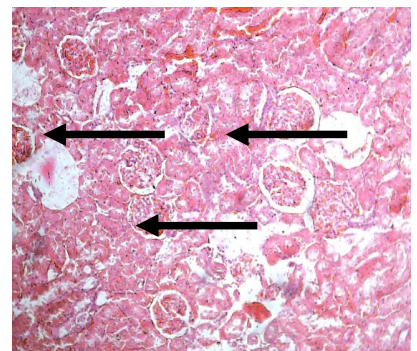

Fig. 4: Section of the kidney of Mus musculus (Control). Section of the kidney showing an area of cortex with numerous renal capsules (arrow) with no evidence of cellular abnormality

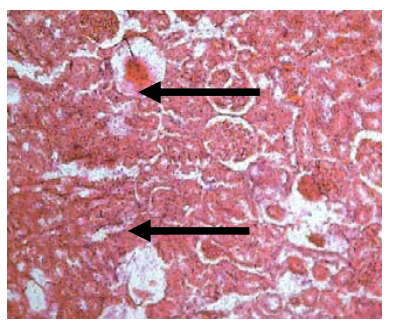

Fig. 5: Section of the kidney of Mus musculus exposed to radiofrequency radiations from GSM base stations over a six months period. The kidney of the exposed mice showed polymorphonuclei cells (white arrows) and distorted renal capsule indicating slight cellular alteration in exposed mice

Therefore, there is no need to implement any fearbased and panicky measures in dealing with the telecom industry. The safety concerns being raised however requires that more studies are needed to reassure the general populace about the safety of these technologies. While it is recognized that scientific inquiries may not be able to prove that any technology is absolutely safe, the bundle of information gathered will enable the regulators to

OTITOLOJU, A A; OSUNKALU, V O; OBE, I A; ADEWALE, O A; AKINDE, O R 
incorporate adequate margin of safety in RF guidelines, such that in events that guidelines are exceeded, severe ill effects will not occur.

Acknowledgements: This research is sponsored by the University of Lagos Central Research Committee grant (CRC No. 2007/18).

Ethics: The experiments carried out involved the utilization of whole and live mice. However, aiming for the protection and welfare of animals, studies were conducted in accordance with University of Lagos Ethics Committee guidelines for experiments with whole animals.

\section{REFERENCES}

Abdel-Rassoul, G., Abou El-Fateh, O., Abou Salem, M., Michael, A., Farahat, F., Batanouny, M. and Salem, E. (2007). Neurobehavioral effects among inhabitants around mobile phone base stations. NeuroToxicology 28: 434-440.

Aitken, R., Bennetts, L., Sawyer, D., Wiklendt, A. and King, B. (2005). Impact of radiofrequency electromagnetic radiation on DNA integrity in the male germline. Int. J. Androl. 28: 171-179.

Barteri, M., Pala, A. and Rotella, S. (2004). Structural and kinetic effects of mobile phone microwaves on acetylcholinesterase activity. Biophysical Chemistry 113: 245-253.

Bortkiewicz, A., Zmyslony, M., Szyjkowska, A. and Gadzicka, E. (2004). Subjective symptoms reported by people living in the vicinity of cellular phone base stations. Rev. Med. Pr 55: 345-351.

Cheever, K.L., Swearengin, T.F., Edwards, R.M., Nelson, B.K., Werren, D.W., Conover, D.L. and Debord, D.G. (2001). 2-Methoxyethanol metabolism, embryonic distribution and macromolecular adduct formation in the rat: the effect of radiofrequency radiation-induced hyperthermia. Toxicology Letters 122: 53-67.

Dasenbrock, C. (2005). Animal carcinogenicity studies on radiofrequency fields related to mobile phones and base stations. Toxicology and Applied Pharmacology 207(2): 342-346.

Diem, E., Schwarz, C., Adlkofer, F., Jahn, O. and Rudiger, H. (2005). Non-thermal DNA breakage by mobile-phone radiation $(1800 \mathrm{MHz})$ in human fibroblasts and in transformed GFSHR17 rat granulose cells in vitro. Mutation Research 583: 178-183.
Garson, O.M., McRobert, T.L., Campbell, L.J., Hocking, B.A. and Gordon, I. (1999). A chromosomal study of workers with long term exposure to radifrequency radiation. Med. J. Aust. 165: 289-292.

Goltsov, A.N. (1999). Electromagnetic-field-induced oscillations of the lipid domain structures in the mixed membranes. Bioelectrochemistry and Bioenergetics 48: 311-316.

Hoffman, M., Blum, A. and Baruch, R., (2004). Leukocytes and coronary heart disease. Atherosclerosis 172: 1-6.

ICNIRP - International Commission on Non-Ionising Radiation Protection (1998). Guidelines for limiting exposure to time-varying magnetic and electromagnetic fields up to $300 \mathrm{GHz}$. Health Physics 74: 494-522.

Jee, S.H., Park, J.Y., Kim, H.S., Lee, T.Y. and Samet, J.M. (2005). White blood cell count and risk for all-cause, cardiovascular, and cancer mortality in a cohort of Koreans. American Journal of Epidemiology 162(11): 1062-1069

Maes, A., Collier, M., Slaets, D. and Verschaeve, L. (1995). Cytogenetic effects of microwaves from mobile communication frequencies $(954 \mathrm{MHz})$. Electromagnetic Biology 14: 91-98.

Markov M, Kostarakis P (2007) Biological effects of electromagnetic fields. Environmentalist 27: 385

Mashevich, M., Folkman, D., Kesar, A., Barbul, A., Korenstein, R. and Jerby, E. (2003). Exposure of human peripheral blood lymphocytes to electromagnetic fields associated with cellular phones leads to chromosomal instability. Bioelectromagnetics 24: 82-90.

Otitoloju A.A., Obe I.A., Adewale O.A., Otubanjo O.A. and Osunkalu, V.O. (2010). Preliminary study on the induction of sperm head abnormalities in mice, Mus musculus, exposed to radiofrequency radiations from global system for mobile communication base stations. Bulletin of Environmental Contamination and Toxicology 84: $51-54$

Pacini, S., Ruggiero, M., Sardi, I., Aterini, S., Gulisano, F. and Gulisano, M. (2002). Exposure to global system for mobile communication (GSM) cellular phone radiofrequency alters gene expression, proliferation and morphology of human skin fibroblasts. Oncol. Res. 13: 19-24. 
Level of Radiofrequency $(R F)$ Radiations.....

Paulraj, R. and Behari, J. (2002). The effect of low level continous $2.45 \mathrm{GHz}$ waves on enzymes of developing rat brain. Electro. Magnetobiol. 21: 221-231.

Philips, J.L., Ivaschuk, O., Ishida-Jones, T., Jones, R.A., Campbell-Beachler, M. and Haggren, W. (1998). DNA damage in molt-4 T-lymphoblastid cells exposed to cellular telephone radiofrequency fields in vitro. Bioelectrochemistry and Bioenergetics 45: 103110.

Pocock, S.J., Ashby, D. and Shaper, A.G. (1989). Diurnal variations in serum biochemical and hematological measurements. Journal of Clinical Pathology 42: 172-179.

Sykes, P.J., McCallum, B.D., Bangay, M.J., Hooker, A.M. and Morley, A.A. (2001). Effect of exposure to $900 \mathrm{MHz}$ radiofrequency radiation on intrachromosomal recombination in pKZ1 mice. Radiation Research 56: 495-502.

Tice, R.R., Hook, G.G., Donner, M., McRee, D.I. and Guy, A.W. (2002). Genotoxicity of radiofrequency signals. I. Investigation of DNA damage and micronuclei induction in cultured human blood cells. Bioelectromangnetics 23: 113-126.

Valberg, P.A., van Deventer, E. and Repacholi, M.H. (2007). Workgroup Report: Base stations and wireless networks - Radiofrequency (RF) exposures and health consequences. Environmental Health Perspectives 115(3): 416424.

Velizarov, S., Raskmark, P. and Kwee, S. (1999). The effects of radiofrequency fields on cell proliferation are non-thermal. Bioelectrochemistry and Bioenergetics 48: 177180. 